\title{
A randomised single-centre trial of inhaled liposomal cyclosporine for bronchiolitis obliterans syndrome post-lung transplantation
}

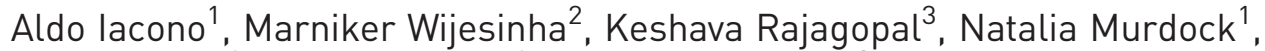 \\ Irina Timofte ${ }^{1}$, Bartley Griffith ${ }^{4}$ and Michael Terrin ${ }^{2}$
}

Affiliations: 'Shock, Trauma and Transplantation and Dept of Medicine, University of Maryland, Baltimore, MD, USA. ${ }^{2}$ Dept of Epidemiology, University of Maryland, Baltimore, MD, USA. ${ }^{3}$ Cardiac Surgery, Memorial Hermann Hospital Texas Medical Center, Houston, TX, USA. ${ }^{4}$ Dept of Cardiothoracic Surgery, University of Maryland, Baltimore, MD, USA.

Correspondence: Aldo lacono, Shock, Trauma and Transplantation and Dept of Medicine, University of Maryland School of Medicine, 22 S. Greene Street, Baltimore, MD 21201, USA. E-mail: aiaconodumm.edu

\section{ABSTRACT}

Introduction: No proven treatments exist for bronchiolitis obliterans syndrome (BOS) following lung transplantation. Inhaled liposomal cyclosporine (L-CsA) may prevent BOS progression.

Methods: A 48-week phase IIb randomised clinical trial was conducted in 21 lung transplant patients with BOS assigned to either L-CsA with standard-of-care (SOC) oral immunosuppression (L-CsA group) or SOC (SOC-alone group). Efficacy end-points were BOS progression-free survival (defined as absence of $\geqslant 20 \%$ decline in forced expiratory volume in $1 \mathrm{~s}\left(\mathrm{FEV}_{1}\right)$ from randomisation, re-transplantation or death) and BOS grade change.

Results: BOS progression-free survival was $82 \%$ for L-CsA versus $50 \%$ for SOC-alone ( $\mathrm{p}=0.1$ ) and BOS grade worsened in $18 \%$ for L-CsA versus $60 \%$ for SOC-alone $(\mathrm{p}=0.05)$. Mean changes in $\Delta \mathrm{FEV}_{1}$ and forced vital capacity, respectively, stabilised with L-CsA: $+0.005(95 \%$ CI $-0.004-+0.013)$ and $-0.005(95 \%$ CI $-0.015-+0.006) \mathrm{L} \cdot \mathrm{month}^{-1}$, but worsened with SOC-alone: -0.023 (95\% CI $-0.033--0.013$ ) and -0.026 (95\% CI $-0.039--0.014) \mathrm{L} \cdot \mathrm{month}^{-1}(\mathrm{p}<0.0001$ and $\mathrm{p}=0.009)$. Median survival (4.1 versus 2.9 years; $\mathrm{p}=0.03)$ and infection rate $(45 \%$ versus $60 \% ; \mathrm{p}=0.7)$ improved with $\mathrm{L}$-CsA versus SOC-alone; creatinine and tacrolimus levels were similar.

Conclusions: L-CsA was well tolerated and stabilised lung function in lung transplant recipients affected by BOS without systemic toxicity, providing a basis for a global phase III trial using L-CsA.

@ERSpublications

Liposomal aerosol cyclosporine (L-CsA) was well tolerated and stabilised lung function in lung transplant recipients affected by BOS. The data provide evidence for an ongoing global phase III trial using L-CsA for BOS. http://bit.ly/2HB8w5j

Cite this article as: Iacono A, Wijesinha M, Rajagopal K, et al. A randomised single-centre trial of inhaled liposomal cyclosporine for bronchiolitis obliterans syndrome post-lung transplantation. ERJ Open Res 2019; 5: 00167-2019 [https://doi.org/10.1183/23120541.00167-2019].

This article has supplementary material available from openres.ersjournals.com

Received: 02 July 2019 | Accepted after revision: 25 Aug 2019

This study is registered at ClinicalTrials.gov with identifier number NCT01650545. Individual participant data will be available after de-identification, including the study protocol, within the first year after article publication. Investigators who propose to use the data will need to be approved by an independent review committee identified for this purpose, for individual participant data for meta-analyses. Proposals may be submitted up to 24 months following article publication.

Copyright @ERS 2019. This article is open access and distributed under the terms of the Creative Commons Attribution Non-Commercial Licence 4.0. 


\section{Introduction}

Outcomes after lung transplantation are poor due to bronchiolitis obliterans [1]. Since bronchiolitis obliterans is not readily demonstrated by lung biopsies, the term bronchiolitis obliterans syndrome (BOS) is applied, defined as a sustained forced expiratory volume in $1 \mathrm{~s}\left(\mathrm{FEV}_{1}\right)$ decline [2]. Treatments for bronchiolitis obliterans are poorly efficacious [3-6]. When higher dosages of calcineurin inhibitors are given for improved immunosuppression, nephrotoxicity and opportunistic infections are limiting [7].

Bronchiolitis obliterans is a complex immunological process triggered by a pathogenetic alloresponse leading to epithelial injury, bronchiolar fibro-obliteration and $\mathrm{FEV}_{1}$ decline [8-10], making the bronchiolar epithelium an interventional target. It has been established that inhalational cyclosporine is deposited in peripheral bronchioles in elevated concentrations [11-13].

In rodent and canine orthotopic lung transplant models, inhaled cyclosporine as single-agent therapy prevents histological rejection in a manner comparable to systemic immunosuppression, with higher intragraft cyclosporine concentrations [14-17]. In humans, numerous clinical trials have shown that inhaled cyclosporine can prevent or ameliorate histological rejection and improve lung function [18-28]. $\mathrm{FEV}_{1}$ improvement has been shown to be dependent on the cyclosporine allograft concentration [21, 27, 28]. Previous studies of inhaled cyclosporine relied on propylene glycol to solubilise cyclosporine with a jet nebuliser, which resulted in adverse respiratory symptoms in up to 50\% of patients [25]. Better tolerated aerosol formulations with quicker delivery and enhanced bioavailability are needed.

This trial, which used a liposomal formulation of aerosolised cyclosporine A (L-CsA), tailored for fast and targeted drug aerosol delivery with a high-performance nebuliser (eFlow), given in addition to standard-of-care (SOC) oral immunosuppression for the treatment of BOS following lung transplantation, is the first randomised controlled study using L-CsA for BOS treatment.

\section{Methods}

\section{Patient characteristics}

This open-label randomised trial was conducted at the University of Maryland (Baltimore, MD, USA) with Institutional Review Board approval. This study is registered at ClinicalTrials.gov with identifier number NCT01650545. The trial was conducted by way of the primary author's (A.I.) Investigational New Drug (IND) application. Enrolment was from September 2012 to January 2015. Follow-up for lung function was for 1 year and survival until September 2017.

Patients $\geqslant 18$ years of age were eligible if recipients of a single or bilateral pulmonary allograft, had clinically diagnosed BOS grade 1 or 2 [2] within 4 weeks of study entry and were receiving tacrolimus-based immunosuppression. Exclusion criteria are listed in the supplementary material. No patient had restrictive chronic lung allograft dysfunction or antibody-mediated rejection prior to or at randomisation, or thereafter $[29,30]$.

\section{Investigational medicinal product}

The product is a drug-device combination: L-CsA and an investigational eFlow nebuliser system (PARI Pharma, Gräfelfing, Germany). L-CsA was supplied in vials of $5 \mathrm{mg} / 1.25 \mathrm{~mL}$ and $10 \mathrm{mg} / 2.5 \mathrm{~mL}$ containing liposomes $\sim 50 \mathrm{~nm}$ diameter (polydispersity index $<0.4$ ) after reconstitution. The eFlow nebuliser produces an aerosol in the respirable range $(2.8-5 \mu \mathrm{m})$. Average inhalation time was $10-15 \mathrm{~min}$.

\section{Treatment regimens}

Conventional oral immunosuppression (SOC) included: tacrolimus $\left(0.06 \mathrm{mg} \cdot \mathrm{kg}^{-1} \cdot \mathrm{day}^{-1}\right)$, mycophenolate mofetil $\left(2000 \mathrm{mg} \mathrm{day}^{-1}\right)$ and prednisone $\left(10-20 \mathrm{mg} \cdot \mathrm{day}^{-1}\right)$. Immunosuppression was adjusted per the University of Maryland protocol (supplementary material). Augmented immunosuppression was given for treatment of histological or clinical rejection consisting of corticosteroids (intravenous methylprednisolone

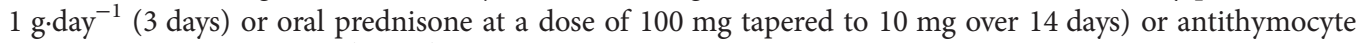
globulin (ATG) $1.5 \mathrm{mg} \cdot \mathrm{kg}^{-1} \cdot \mathrm{day}^{-1}$ (3-5 days).

Patients randomised to the L-CsA arm were scheduled to receive L-CsA twice daily for 24 weeks at doses of $5 \mathrm{mg}$ (single allograft) or $10 \mathrm{mg}$ (double allograft), in addition to SOC. After the initial 24-week treatment period, patients in the L-CsA arm continued on SOC during a subsequent 24-week follow-up. Patients randomised to the SOC-alone arm received standard immunosuppression only.

\section{Trial design and evaluations}

The objective of the study was to evaluate safety and efficacy of L-CsA for grade 1 and 2 BOS. Because single lung recipients have a worse outcome, randomisation was stratified according to single and bilateral status. Patients were then randomly assigned to groups according to block randomisation in a 1:1 ratio to 
receive either L-CsA or SOC-alone. Study treatment began as soon as possible after randomisation, typically within 7 days. If SOC-alone patients met a primary end-point of $\geqslant 20 \%$ decline in $\mathrm{FEV}_{1}$ from randomisation and still met initial study entry criteria, L-CsA was permitted as "rescue" crossover. Additionally, if this efficacy end-point occurred during the second 24-week follow-up period after L-CsA administration in that arm, L-CsA could then be re-initiated for a second 24-week period. Crossover patients in both arms were followed clinically, but their data were included in the study analyses end-points up until they met a primary study end-point.

\section{End-points}

There were two primary end-points: 1) a composite of BOS progression-free survival, defined as time from randomisation to $\geqslant 20 \%$ decline in $\mathrm{FEV}_{1}$, re-transplantation or death, whichever occurred first (prolonged mechanical ventilation and irreversible respiratory failure equivalent to $\geqslant 20 \%$ decline of $\mathrm{FEV}_{1}$ ), and 2) BOS grade progression by grade changes from randomisation to study completion. A decline in $\mathrm{FEV}_{1}$ was validated for absence of concurrent illness measured at intervals $\geqslant 3$ weeks apart.

Other exploratory end-points included change in lung function, quantitation of histological bronchiolitis obliterans and bronchoalveolar lavage (BAL) cytokine measurements (interleukin (IL)-1 $\beta$, IL-2, IL-6, IL-8, IL-10, IL-17, interferon (IFN) $-\gamma$ and tumour necrosis factor (TNF)- $\alpha$ )) by multiplex assay (Luminex 100 system; Luminex, Austin, TX, USA) analysed using Bio-Plex Manager (Bio-Rad, Hercules, CA, USA). BAL was performed before randomisation, at week 24, and when indicated clinically [2].

\section{Safety}

Patient and graft survival and adverse events including infections and symptoms related to L-CsA were quantified as an index of safety and compared between study arms. An Outcomes and Safety Committee adjudicated events.

\section{Statistical analysis}

As the first phase IIb trial using L-CsA for BOS treatment, the number of patients to be randomised was determined by the availability of L-CsA and other resources. The IND study specified the end-points, safety measures and a 3-year enrolment period of 30 patients. No modifications were made after trial initiation. 15 patients per group was deemed appropriate, as absence of the desired outcomes for L-CsA would discourage future drug development. Enrolment of qualifying recipients was discontinued after 3 years after accrual of 21 subjects. The target enrolment goal was not met due to lower than anticipated enrolment rates. Outcome data collection continued until either a primary outcome event occurred or patients without events completed the study at 48 weeks. Patient and graft survival were monitored until September 2017 as an assessment of safety independent of continuation or discontinuation of L-CsA. Patients were analysed according to the intention-to-treat principle. No patient was lost to follow-up.

End-point events were compared by Kaplan-Meier survival analyses and log-rank testing as specified $a$ priori by our protocol. A p-value of $<0.05$ indicated statistical significance. Since the patient survival analysis showed nonproportionality, the Renyi statistic was also used. Data are presented with hazard ratios and 95\% confidence intervals. For lung function analyses, multivariate linear mixed effects statistical models (PROC MIXED in SAS version 9.1.3; SAS Institute, Cary, NC, USA) were utilised [31]. Secondary end-points included lung function changes, infection rates and survival. For lung function, as pre-specified for single and bilateral lungs, one mixed model was based only on post-randomisation lung function data using a longitudinal regression model, while a second model accounted for intragroup values pre-randomisation adjusting for within-patient trends that could potentially influence post-randomisation function. Changes in cytokine measurements from pre- to post-randomisation were compared using two-way ANOVA from 42 BAL collections (21 in each group). Sirolimus and tacrolimus levels and routine laboratory values were compared using a mixed effects model. A total of 243 pulmonary function tests (122 L-CsA and 121 SOC-alone) and 603 blood samples were analysed.

\section{Results}

\section{Patient characteristics}

Of 43 patients screened, 17 failed to meet BOS grade criteria and 21 were randomised (11 to L-CsA and 10 to SOC-alone) (figure 1). Baseline characteristics and clinical management of the two groups were similar, although more cytomegalovirus mismatches were randomised to L-CsA (table 1). Mean \pm SD time to BOS confirmation for L-CsA was comparable to SOC-alone ( $1391 \pm 859$ versus $1061 \pm 796$ days; $\mathrm{p}=0.41)$. Forced vital capacity (FVC) decline prior to randomisation for both L-CsA and SOC-alone was similar $(-0.025$ (95\% CI $-0.034-0.015)$ versus -0.021 (95\% CI $-0.030--0.012) \mathrm{L} ; \mathrm{p}=0.69)$. Azithromycin use, induction cycles, BOS grades and absolute $\mathrm{FEV}_{1}$ decline rates prior to randomisation were all similar (supplementary material). All randomised patients reached the efficacy end-point or completed 48 weeks 


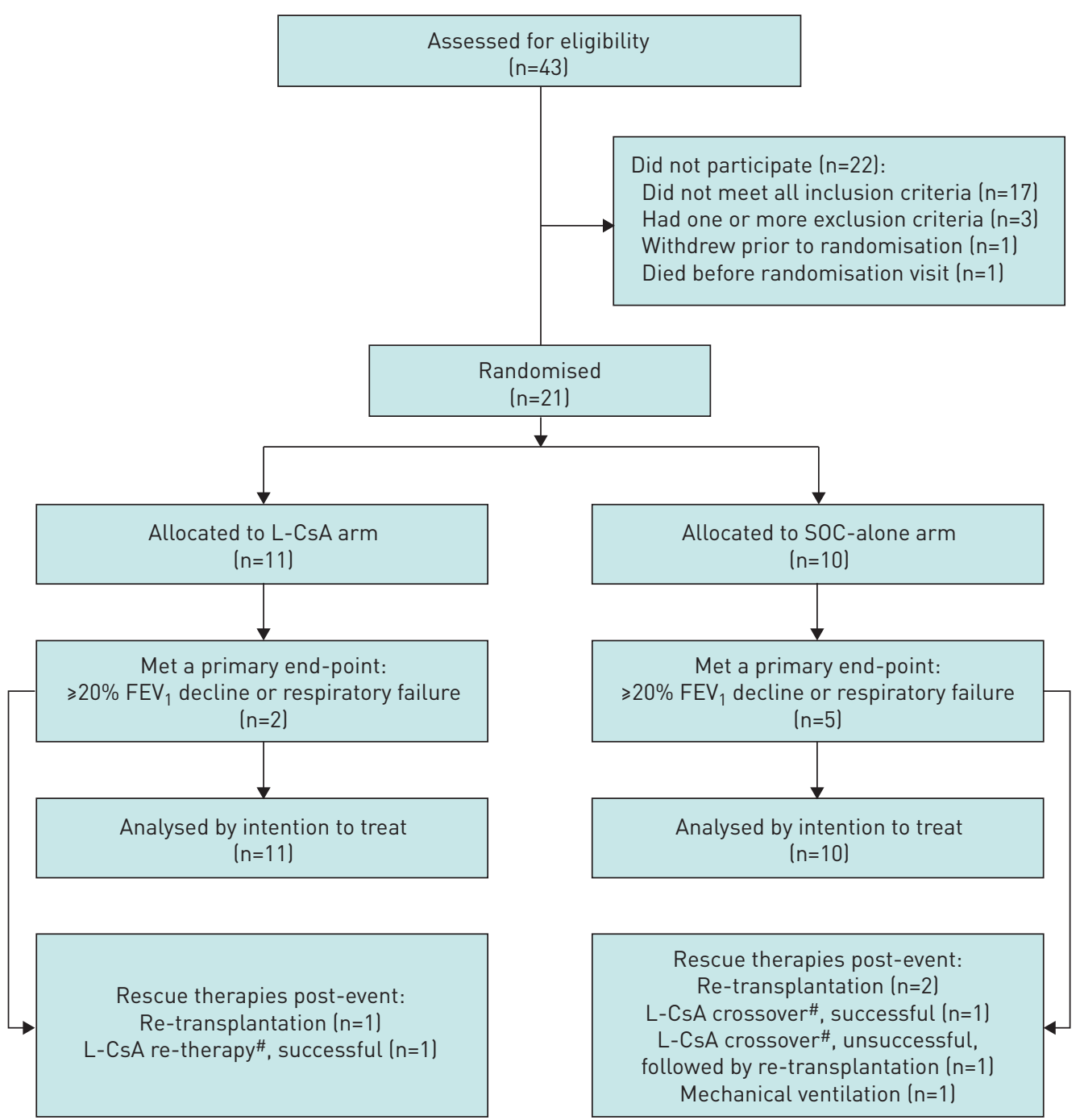

FIGURE 1 Study enrolment. L-CSA: liposomal cyclosporine; SOC: standard of care; FEV $\mathrm{F}_{1}$ forced expiratory volume in $1 \mathrm{~s}$; BOS: bronchiolitis obliterans syndrome. 43 patients were assessed for eligibility for this study. 17 screened patients did not meet BOS grade 1 or 2 criteria and three patients met exclusion criteria. 23 patients met eligibility criteria. One patient died and one patient withdrew prior to randomisation. 21 patients were randomised: 11 patients to the inhaled L-CsA treatment arm given in addition to conventional oral immunosuppression (SOC) and 10 patients to the SOC-alone arm. Patients were followed until an efficacy end-point occurred la $\geqslant 20 \% \mathrm{FEV}_{1}$ decline or re-transplantation or death) or until week 48 . If the efficacy end-point event occurred before week 48 in the SOC-alone arm, crossover to L-CsA was permitted. If the efficacy end-point occurred in the L-CsA group during the 24-week observation interval only, re-treatment with L-CsA was possible if patients still fulfilled eligibility criteria. One SOC-alone patient developed protracted respiratory failure ( $>3$ weeks duration) due to progressive BOS. \#: the mean duration of L-CsA crossover or re-therapy was 156 days la successful L-CsA "crossover" or "re-therapy" was defined as absence of $\geqslant 20 \% \mathrm{FEV}_{1}$ decline relative to the time of initiation, according to the end-point definition).

of follow-up. Both the L-CsA and SOC-alone groups received similar cycles of augmentation of immune suppression after randomisation (three steroid pulses and one ATG cycle). Five patients has positive donor-specific antibody results post-transplantation: two patients in L-CsA and three in SOC-alone (three with human leukocyte antigen class 2 reactivity).

\section{BOS progression}

Mean $\pm \mathrm{SD} \mathrm{FEV}_{1}$ changes from baseline maximal values were similar at randomisation for L-CsA versus SOC-alone $(-31.2 \pm 9 \%$ and $-31.8 \pm 6.8 \% ; \mathrm{p}=0.8)$. BOS progression-free survival was observed in nine out of $11(82 \%)$ patients treated with L-CsA versus five out of $10(50 \%)$ SOC-alone patients (hazard ratio 3.19 (95\% CI 0.62-16.50); $\mathrm{p}=0.1$ ) (figure 2a). Only one L-CsA patient met this primary end-point while receiving L-CsA; the second met the end-point while off L-CsA (following the initial 24-week 


\begin{tabular}{|c|c|c|c|}
\hline & L-CsA & SOC-alone & p-value \\
\hline Subjects & 11 & 10 & \\
\hline Age years & $59.1 \pm 13.7$ & $63.8 \pm 13.1$ & 0.4 \\
\hline Sex & & & 0.4 \\
\hline Female & $5(45)$ & $2(20)$ & \\
\hline Male & $6(55)$ & $8(80)$ & \\
\hline Race & & & $>0.9$ \\
\hline African-American & 3 (27) & $2(20)$ & \\
\hline Caucasian & $8(73)$ & $8(80)$ & \\
\hline Lung disease & & & $>0.9$ \\
\hline COPD & 3 (27) & $3(30)$ & \\
\hline Pulmonary fibrosis & $7(64)$ & $6(60)$ & \\
\hline Pulmonary hypertension & $0(0)$ & $1(10)$ & \\
\hline Sarcoidosis & $1(9)$ & $0(0)$ & \\
\hline Transplant type & & & 0.7 \\
\hline Single & 5 (45) & $6(60)$ & \\
\hline Double & $6(55)$ & $4(40)$ & \\
\hline \multicolumn{4}{|l|}{ Immunosuppression } \\
\hline \multicolumn{4}{|l|}{ Tacrolimus } \\
\hline Patients & 8 & 10 & \\
\hline Level $\mathrm{ng} \cdot \mathrm{mL}^{-1}$ & $9.9 \pm 3.1$ & $7.7 \pm 3.7$ & 0.2 \\
\hline \multicolumn{4}{|l|}{ Sirolimus } \\
\hline Patients & 3 & 4 & \\
\hline Level $\mathrm{ng} \cdot \mathrm{mL}^{-1}$ & $7.2 \pm 3.8$ & $7.1 \pm 4.9$ & $>0.9$ \\
\hline Azithromycin & 6 & 7 & 0.7 \\
\hline \multicolumn{4}{|l|}{ Laboratory results } \\
\hline Creatinine $\mathrm{mg} \cdot \mathrm{dL}^{-1}$ & $1.6 \pm 0.5$ & $1.4 \pm 0.4$ & 0.3 \\
\hline White blood cell count $\times 10^{9} \mathrm{~L}^{-1}$ & $7.2 \pm 2.3$ & $7.9 \pm 2.9$ & 0.6 \\
\hline Platelet count $\times 10^{9} \mathrm{~L}^{-1}$ & $238.2 \pm 92.8$ & $214.0 \pm 64.9$ & 0.5 \\
\hline Alanine transaminase $\mathrm{U} \cdot \mathrm{L}^{-1}$ & $26.6 \pm 14.4$ & $30.6 \pm 15.4$ & 0.6 \\
\hline Aspartate transaminase $\mathrm{U} \cdot \mathrm{L}^{-1}$ & $32.2 \pm 14.4$ & $29.4 \pm 12.0$ & 0.7 \\
\hline Bilirubin $\mathrm{mg} \cdot \mathrm{dL}^{-1}$ & $0.4 \pm 0.1$ & $0.4 \pm 0.2$ & 0.5 \\
\hline Haemoglobin $\mathrm{g} \cdot \mathrm{dL}^{-1}$ & $11.8 \pm 2.0$ & $11.5 \pm 1.6$ & 0.7 \\
\hline Haematocrit \% & $36.8 \pm 6.1$ & $35.1 \pm 4.5$ & 0.5 \\
\hline \multicolumn{4}{|l|}{ Donor (D)-recipient (R) matching } \\
\hline HLA mismatches & $4.3 \pm 1.2$ & $4.6 \pm 1.2$ & 0.6 \\
\hline Cytomegalovirus & & & 0.4 \\
\hline $\mathrm{R}+/ \mathrm{D}+$ & 3 & 2 & \\
\hline $\mathrm{R}+/ \mathrm{D}_{-}$ & 4 & 4 & \\
\hline $\mathrm{R}-/ \mathrm{D}+$ & 3 & 0 & \\
\hline $\mathrm{R}-/ \mathrm{D}-$ & 1 & 4 & \\
\hline \multicolumn{4}{|l|}{ Donor characteristics } \\
\hline Age years & $32.4 \pm 11.8$ & $32.8 \pm 11.3$ & $>0.9$ \\
\hline Sex & & & 0.6 \\
\hline Female & $4(36)$ & $2(20)$ & \\
\hline Male & $7(64)$ & $8(80)$ & \\
\hline Race & & & 0.4 \\
\hline African-American & $5(45)$ & $2(20)$ & \\
\hline Caucasian & $6(55)$ & $8(80)$ & \\
\hline Smoking history $\geqslant 20$ pack-years & & & 0.5 \\
\hline Yes & 2 & 0 & \\
\hline No & 8 & 10 & \\
\hline Unknown & 1 & 0 & \\
\hline Ischaemic time $\mathrm{h}$ & $4.69 \pm 2.02$ & $5.53 \pm 3.00$ & 0.5 \\
\hline \multicolumn{4}{|l|}{ Pulmonary function } \\
\hline $\mathrm{FEV}_{1}$ at randomisation $\mathrm{L}$ & $1.66 \pm 0.56$ & $1.78 \pm 0.60$ & 0.7 \\
\hline BOS grade at randomisation & & & $>0.9$ \\
\hline 1 & $7(64)$ & $7(70)$ & \\
\hline 2 & $4(36)$ & $3(30)$ & \\
\hline
\end{tabular}




\begin{tabular}{|c|c|c|c|}
\hline & L-CsA & SOC-alone & p-value \\
\hline Time from transplantation to diagnosis of BOS days & $1391 \pm 859$ & $1061 \pm 796$ & 0.4 \\
\hline Time from transplantation to randomisation days & $1417.7 \pm 852.4$ & $1097.0 \pm 788.0$ & 0.4 \\
\hline$\Delta \mathrm{FEV}_{1}$ from transplantation to randomisation L-month ${ }^{-1}$ & $-0.003 \pm 0.004$ & $-0.008 \pm 0.002$ & 0.2 \\
\hline \multicolumn{4}{|c|}{$\begin{array}{l}\text { Data are presented as } n \text {, mean } \pm S D \text { or } n(\%) \text {, unless otherwise stated. COPD: chronic obstructive pulmonary } \\
\text { disease; HLA: human leukocyte antigen; } \mathrm{FEV}_{1} \text { : forced expiratory volume in } 1 \mathrm{~s} ; \mathrm{BOS} \text { : bronchiolitis } \\
\text { obliterans syndrome. }\end{array}$} \\
\hline
\end{tabular}

on-treatment period) and stabilised after L-CsA was resumed (a "rescue" crossover). Of the five end-point occurrences in the SOC-alone group, two patients were re-transplanted, one developed respiratory failure and one out of two patients who crossed over from SOC-alone responded to L-CsA without further interventions. BOS grade progression from randomisation occurred three-fold less commonly in patients receiving $\mathrm{L}-\mathrm{CsA}$ versus SOC-alone ( $\mathrm{p}=0.05)$ (figure $2 \mathrm{~b}$ ).

Lung function changes prior to randomisation and after L-CsA

$\triangle \mathrm{FEV}_{1}$ post-randomisation demonstrated stability with L-CsA $(+0.005 \quad(95 \% \quad \mathrm{CI} \quad-0.004-$ $\left.+0.013) \mathrm{L} \cdot \mathrm{month}^{-1}\right)$ compared with SOC-alone $\left(-0.023(95 \% \mathrm{CI}-0.033--0.013) \mathrm{L} \cdot \mathrm{month}^{-1} ; \mathrm{p}<0.0001\right)$ (figure 3a). Additionally, within randomised groups, $\triangle \mathrm{FEV}_{1}$ showed improvement after randomisation to $\mathrm{L}$-CsA compared with deterioration prior to study treatment $\left(\Delta \mathrm{FEV}_{1}\right.$ pre-randomisation $-0.021(95 \% \mathrm{CI}$ $-0.032-0.011) \mathrm{L} \cdot \mathrm{month}^{-1}$ versus post-randomisation +0.005 (95\% CI $\left.-0.004-+0.013\right) \mathrm{L} \cdot \mathrm{month}^{-1}$; $\mathrm{p}=0.0002$ ). In contrast, patients in the SOC-alone group had continued $\mathrm{FEV}_{1}$ decline post-randomisation comparable to pre-randomisation $\left(\Delta \mathrm{FEV}_{1}\right.$ pre-randomisation $-0.028(95 \% \mathrm{CI}-0.039--0.018) \mathrm{L} \cdot \mathrm{month}^{-1}$ versus post-randomisation $\left.-0.025(95 \% \mathrm{CI}-0.035--0.015) \mathrm{L} \cdot \mathrm{month}^{-1} ; \mathrm{p}=0.3\right)$ (figure $\left.3 \mathrm{~b}\right)$.

$\triangle$ FVC similarly showed improvement post-randomisation for L-CsA and decline for SOC-alone $\left(\mathrm{L}-\mathrm{CsA} \quad-0.005 \quad(95 \% \quad \mathrm{CI} \quad-0.015-+0.006) \mathrm{L} \cdot \mathrm{month}^{-1} \quad\right.$ versus $\mathrm{SOC}$-alone $\quad-0.026 \quad(95 \% \quad \mathrm{CI}$ $-0.039--0.014) \mathrm{L} \cdot \mathrm{month}^{-1} ; \mathrm{p}=0.009$ ) (figure 3c). For the change in forced expiratory flow at $25-75 \%$ of FVC $\left(\Delta \mathrm{FEF}_{25-75 \%}\right)$, a similar pattern was shown post-randomisation for L-CsA $(+0.008(95 \%$ CI $\left.-0.015-+0.031) \mathrm{L} \cdot \mathrm{month}^{-1}\right)$ versus SOC-alone $\left(-0.015(95 \% \mathrm{CI}-0.042-+0.011) \mathrm{L} \cdot \mathrm{month}^{-1}\right)(\mathrm{p}=0.1)$ (figure $3 \mathrm{~d}$ ). Of the three subjects for whom L-CsA was administered as a rescue therapy (re-initiated for $\mathrm{L}$-CsA or crossover from SOC-alone), the $\triangle \mathrm{FEV}_{1}$ slope after L-CsA rescue at 24 weeks was $+0.01(95 \% \mathrm{CI}$ 0.003-0.018) L·month ${ }^{-1}$.
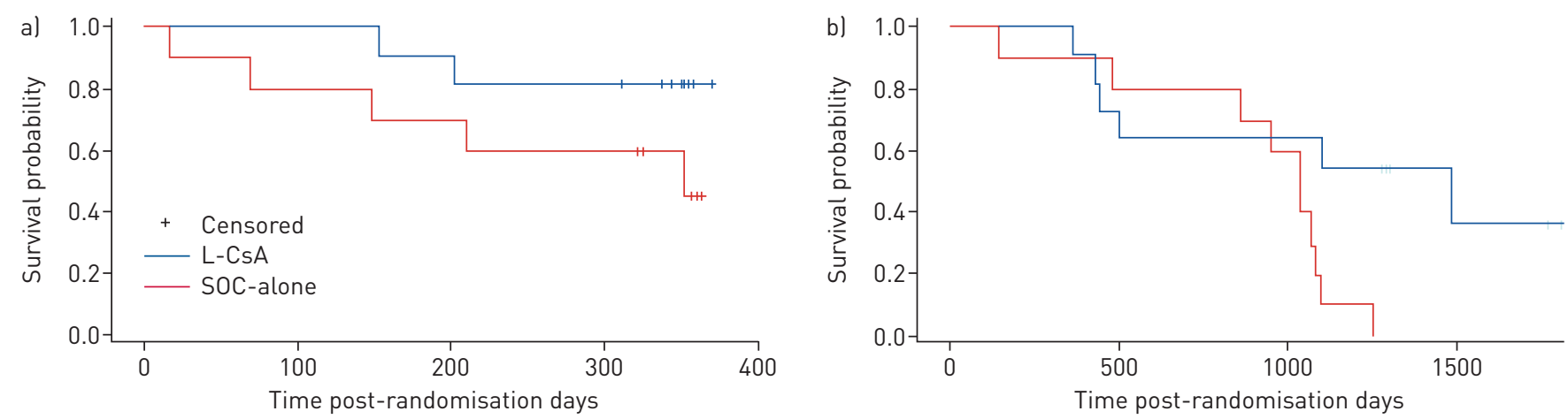

FIGURE 2 a) One efficacy end-point of the study was bronchiolitis obliterans syndrome (BOS) progression-free survival, defined as time after randomisation to a $\geqslant 20 \%$ forced expiratory volume in $1 \mathrm{~s}\left(\mathrm{FEV}_{1}\right)$ decline, re-transplantation or death, whichever occurred first. (Prolonged mechanical ventilation due to respiratory failure was considered equivalent to a $\geqslant 20 \%$ decline in FEV , $_{1}$ ) Five out of 10 patients $(50 \%)$ in the standard of care (SOC)-alone arm experienced treatment failure compared with two out of $11(18 \%)$ patients randomised to L-CsA (SOC versus $\mathrm{L}-\mathrm{CsA}$ hazard ratio 3.19 (95\% $\mathrm{Cl} 0.62-16.50) ; \mathrm{p}=0.1)$. A decline in $\mathrm{FEV}_{1}$ was validated for concurrent lung or other illnesses other than $\mathrm{B} 0 \mathrm{~S}$, and measured and confirmed at intervals of $\geqslant 3$ weeks apart. The baseline study FEV 1 used was the value obtained from randomisation. b) Number of patients alive as of September 12, 2017: five out of $11(45 \%)$ in the L-CsA arm versus none out of $10(0 \%)$ in the SOC-alone arm ( $p=0.03)$. The other efficacy end-point was change in BOS grades from randomisation to study completion at 48 weeks. Patient changes in BOS grade during the 48-week study period, from baseline grade at randomisation, in the L-CsA and SOC-alone arms. A three-fold reduction in the grade of BOS progression, indicating functional BOS disease stability by L-CsA, was demonstrated in patients treated with L-CsA compared with those who received SOC-alone ( $p=0.05)$. 

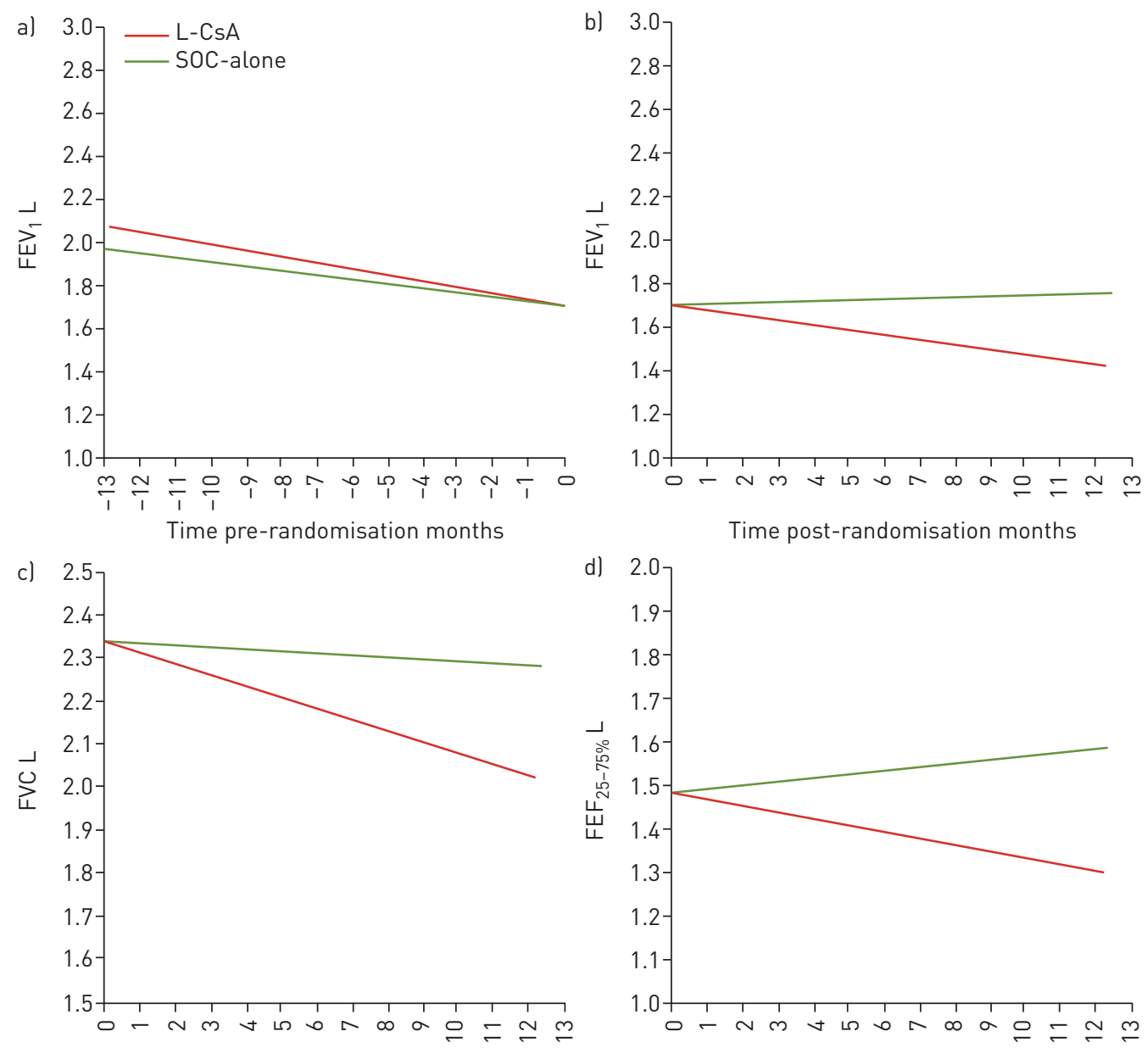

Time post-randomisation months

Time post-randomisation months

FIGURE $3 \mathrm{a}$, b) Comparisons of forced expiratory volume in $1 \mathrm{~s}\left(\mathrm{FEV}_{1}\right)$ over time, analysed by multivariate linear mixed effects in the liposomal cyclosporine (L-CSA) and standard of care (SOC)-alone arms, analysed a) before and b) after randomisation to the respective arms of the trial. In the year prior to randomisation, $\mathrm{FEV}_{1}$ slopes were similar between the $\mathrm{L}-\mathrm{CsA}$ and $\mathrm{SOC}$-alone groups (pre-randomisation $\triangle \mathrm{FEV} \mathrm{V}_{1}-0.021(95 \%$ $\mathrm{Cl}-0.032--0.011)$ versus $\left.-0.028(95 \% \mathrm{Cl}-0.039--0.018) \mathrm{L} \cdot \mathrm{month}^{-1} ; \mathrm{p}=0.3\right)$. The post-randomisation $\Delta \mathrm{FEV}$, demonstrated stability for the L-CsA arm $\left(+0.005(95 \% \mathrm{Cl}-0.004-+0.013) \mathrm{L} \cdot \mathrm{month}^{-1}\right)$ compared with significant deterioration in the SOC-alone $\operatorname{arm}\left(-0.025(95 \% \mathrm{Cl}-0.035--0.015) \mathrm{L} \cdot \mathrm{month}^{-1}\right)(\mathrm{p}<0.0001)$. Within-group pre- and post-randomisation FEV ${ }_{1}$ analyses (L-CsA and SOC-alone, analysed distinctly) demonstrated improvement in patients after randomisation to L-CsA compared with $\triangle \mathrm{FEV} 1$ decline prior to randomisation while receiving SOC-alone (pre-randomisation $\triangle \mathrm{FEV} 1 \quad-0.021 \quad 195 \% \quad \mathrm{Cl}$ $-0.032-0.011) \mathrm{L} \cdot \mathrm{month}^{-1}$ versus post-randomisation $\left.+0.005(95 \% \mathrm{Cl}-0.004-+0.013) \mathrm{L} \cdot \mathrm{month}^{-1} ; \mathrm{p}=0.0002\right)$. In contrast, patients in the SOC-alone arm demonstrated continued $\mathrm{FEV}_{1}$ decline after randomisation similar to pre-randomisation values (pre-randomisation $\Delta \mathrm{FEV}{ }_{1}-0.028(95 \% \mathrm{Cl}-0.039-0.018) \mathrm{L} \cdot \mathrm{month}^{-1}$ versus post-randomisation $-0.025(95 \% \mathrm{Cl}-0.035-0.015) \mathrm{L} \cdot$ month $\left.^{-1} ; \mathrm{p}=0.3\right)$. c, d) Comparisons of c) forced vital capacity (FVC) and d) forced expiratory flow at 25-75\% of FVC (FEF $25-50 \%$ ) over the 48-week post-randomisation period in the L-CsA and SOC-alone arms, analysed after randomisation and compared between patient groups with their respective arms of the trial. For $\triangle \mathrm{FVC}, \mathrm{L}-\mathrm{C}$ sA versus SOC-alone: -0.005 $(95 \% \mathrm{Cl}-0.015-+0.006)$ and $\left.-0.026(95 \% \mathrm{Cl}-0.039-0.014) \mathrm{L} \cdot \mathrm{month}^{-1}\right)(\mathrm{p}=0.009)$. For $\Delta \mathrm{FEF}_{25-75 \%} \mathrm{~L}-\mathrm{CsA}$ versus SOC-alone: $+0.008(95 \% \mathrm{Cl}-0.015-+0.031)$ and $-0.015(95 \% \mathrm{Cl}-0.042-+0.011) \mathrm{L} \cdot \mathrm{month}^{-1}(\mathrm{p}=0.1)$.

\section{BAL cytokines}

Cytokines measured were similar before randomisation between the L-CsA and SOC-alone groups. The following cytokines were significantly different after randomisation in L-CsA versus SOC-alone (median (interquartile range)): IL-2 7.1 (0.5-7.1) versus $48.4(11.3-55.2) \mathrm{pg} \cdot \mathrm{mL}^{-1}(\mathrm{p}=0.04)$, IL-10 $3.3(0-13.0)$ versus $0(0-2.5) \mathrm{pg} \cdot \mathrm{mL}^{-1}(\mathrm{p}=0.04)$ and IFN- $\gamma 3.8(0.2-37.6)$ versus $0.8(0.7-4.4) \mathrm{pg} \cdot \mathrm{mL}^{-1}(\mathrm{p}=0.05)$ (figure 4). IL-1 $\beta$, IL-6, IL-8, IL-17 and TNF- $\alpha$ showed no significant differences before or during the study.

\section{Systemic immune suppression}

Maintenance tacrolimus blood levels and doses and prednisone doses were similar at baseline (table 1) and at study completion for L-CsA and SOC-alone: tacrolimus levels 6.32 (95\% CI 4.57-8.07) versus 5.19 (95\% 

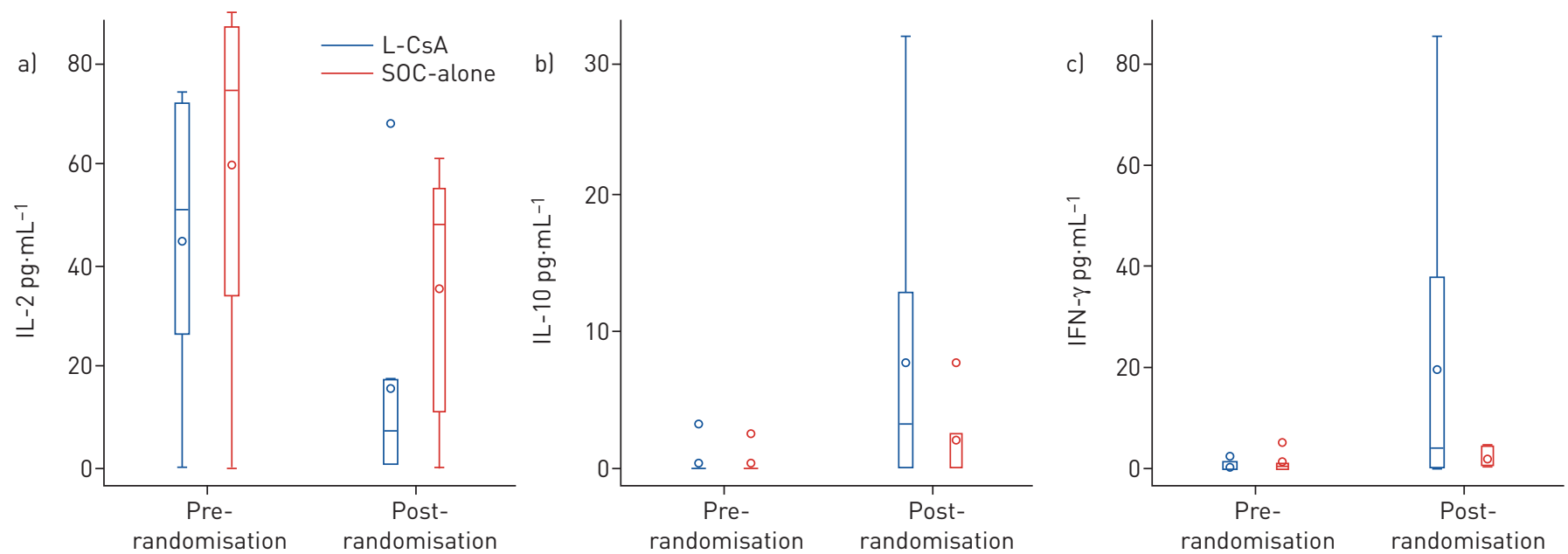

FIGURE 4 A comparison of a) interleukin (IL)-2, b) IL-10 and c) interferon (IFN)- $\gamma$ cytokines between the liposomal cyclosporine (L-CsA) and standard of care (SOC)-alone arms, pre- and post-randomisation during the 48-week follow-up. Data are presented as median with interquartile range (IQR) (boxes), together with minimum and maximum values (whiskers); the circle within a box represents the mean, while circles outside of a box represent outliers. Compared with SOC-alone, the post-randomisation changes in IL-2, IL-10 and IFN- $\gamma$ (analysed by two-way ANOVA) were significantly different in the L-CsA group, with post-randomisation values (median (interquartile range)): IL-2 7.1 (0.5-17.1) pg.mL ${ }^{-1}$ in $\mathrm{L}-\mathrm{Cs} A$ versus $48.4(11.3-55.2) \mathrm{pg} \cdot \mathrm{mL}^{-1}$ in SOC-alone $(\mathrm{p}=0.04), \mathrm{IL}-103.3(0-13.0) \mathrm{pg} \cdot \mathrm{mL}^{-1}$ in $\mathrm{L}-\mathrm{CsA}$ versus $0(0-2.5) \mathrm{pg} \cdot \mathrm{mL}^{-1}$ in $\mathrm{SOC}-\mathrm{alone}(\mathrm{p}=0.04)$ and IFN- $\gamma 3.8(0.2-37.6) \mathrm{pg} \cdot \mathrm{mL}^{-1}$ in $\mathrm{L}-\mathrm{Cs} A$ versus $0.8(0.7-4.4) \mathrm{pg} \cdot \mathrm{mL}^{-1}$ in $\mathrm{SOC}$-alone $(\mathrm{p}=0.05)$. All other cytokines measured, including IL-1 $\beta$, IL-6, IL-8, IL-17 and tumour necrosis factor- $\alpha$, showed no significant differences post-randomisation between patients randomised to L-CsA versus SOC-alone.

CI $3.08-7.30) \mathrm{ng} \cdot \mathrm{mL}^{-1} \quad(\mathrm{p}=0.4)$, tacrolimus doses $2.0 \quad(95 \%$ CI $1.4-2.7) \quad$ versus $2.5 \quad(95 \%$ CI 1.8-3.1) $\mathrm{mg}^{-1 \mathrm{day}^{-1}}(\mathrm{p}=0.1)$ and prednisone doses $11.6 \quad(95 \%$ CI $9.0-14.0)$ versus $9.9 \quad(95 \%$ CI 7.0-12.7) $\mathrm{mg}^{-\mathrm{day}^{-1}}(\mathrm{p}=0.3)$. Augmentation cycles did not differ between the treatment arms before or after randomisation. Sirolimus blood levels were lower in L-CsA compared with SOC-alone at study completion (2.65 (95\% CI 0.00-5.73) versus 9.29 (95\% CI 7.06-11.51) ng.mL $\mathrm{mL}^{-1}$; $\left.\mathrm{p}=0.0007\right)$, but were similar at randomisation (table 1).

\section{Histopathology before and after randomisation to L-CSA}

Transbronchial biopsies were performed when indicated by the University of Maryland protocol. Prior to randomisation, histology demonstrated four cases with airway rejection in L-CsA cases (two patients B1 and two patients with histological changes suggestive of bronchiolitis obliterans) and only one receiving SOC-alone (one patient with changes suggestive of bronchiolitis obliterans). Post-randomisation, four patients receiving SOC-alone had airway rejection (two patients B2 and two patients B1), whereas two patients receiving L-CsA had B1 airway rejection. One patient receiving L-CsA and two patients receiving SOC-alone experienced grade 1 acute rejection. No patient had histopathological changes consistent with antibody-mediated rejection or positive $\mathrm{C} 4 \mathrm{~d}$ staining prior to or after randomisation.

\section{Pharmacokinetics}

Cyclosporine blood sampling was done for all patients randomised to L-CsA and one crossover patient. Mean \pm SD maximum cyclosporine blood concentration $\left(C_{\max }\right)$ was $57.42 \pm 34.26 \mathrm{ng} \cdot \mathrm{mL}^{-1}$ achieved after 15-30 $\min \left(t_{\max }\right)$ and the half-life $\left(t_{1 / 2}\right)$ was $\sim 2 \mathrm{~h}$. At $24 \mathrm{~h}$, mean \pm SD cyclosporine blood concentration was $1.42 \pm 4.91 \mathrm{ng} \cdot \mathrm{mL}^{-1}$.

\section{Adverse events}

No adverse event required withdrawal from L-CsA or permanent drug discontinuation. No patient was lost to follow-up. Peak expiratory flow (PEF) at the first dosing was $367.7 \mathrm{~L} \cdot \mathrm{min}^{-1}$ prior to inhalation and 327.7 $\mathrm{L} \cdot \mathrm{min}^{-1}$ after inhalation $(-10.9 \%$ decrease). No patients met the pre-specified PEF $20 \%$ decline criterion to discontinue L-CsA. Three adverse events were related to L-CsA: conjunctivitis, pharyngitis and productive cough.

Mean creatinine at end of follow-up (week 48) for L-CsA and SOC-alone was 1.52 (95\% CI 1.31-1.73) versus $1.65(95 \%$ CI $1.41-1.89) \mathrm{mg} \cdot \mathrm{dL}^{-1}(\mathrm{p}=0.3)$. Aspartate transaminase (AST), alanine transaminase (ALT) and bilirubin remained within reference ranges (AST $14-36 \mathrm{U} \cdot \mathrm{L}^{-1}$, ALT $9-52 \mathrm{U} \cdot \mathrm{L}^{-1}$ and bilirubin 0.3-1.2 $\mathrm{mg} \cdot \mathrm{dL}^{-1}$ ) in both arms. Serious adverse events occurred with nearly equal frequency for L-CsA and SOC-alone (22 versus 24 events). Four pneumonia events occurred, all in the SOC-alone group. There 

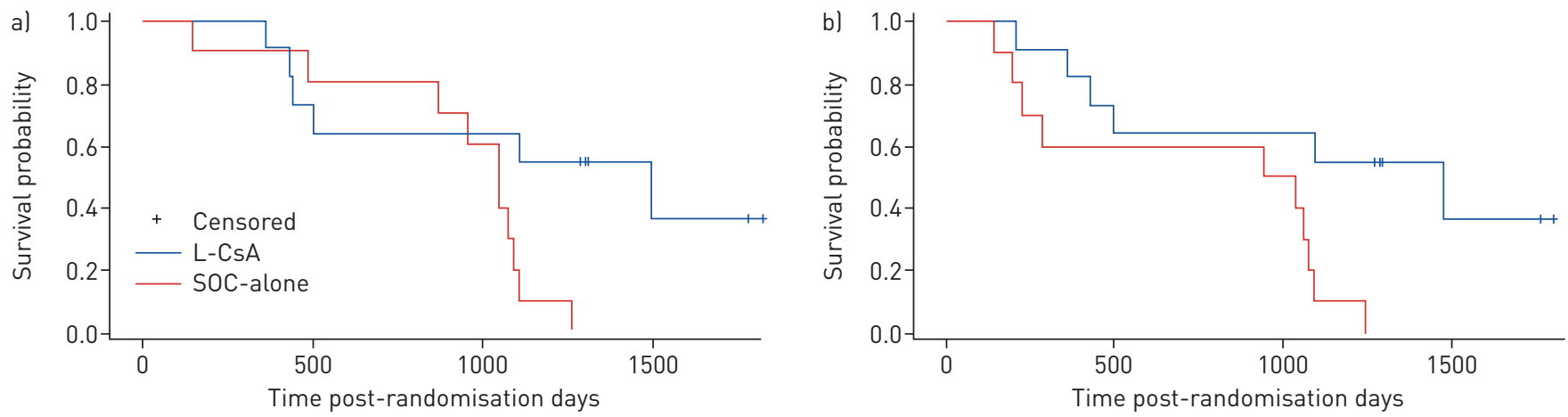

FIGURE 5 a) A comparison of long-term patient survival between the treatment groups. L-CsA: liposomal cyclosporine; SOC: standard of care. As of September 2017, 45\% of patients (five out of 11) randomised to the inhaled L-CsA arm were alive, while 0\% of patients (none out of 10) randomised to the SOC-alone arm were alive $(p=0.03)$. Median patient survival was 4.1 years for L-CsA compared with 2.9 years for SOC-alone. b) A comparison of long-term graft survival between the treatment groups. As of September 2017, 45\% of patients (five out of 11) randomised to the L-CsA arm were alive and free of re-transplantation (one re-transplantation occurred) compared with $0 \%$ of patients (none out of 10) randomised to the SOC-alone arm (three re-transplantations occurred) ( $p=0.01$ ). Median graft survival was 4.1 years for L-CsA compared with 2.7 years for SOC-alone.

was no difference in infection rates: five out of $11(45 \%)$ and six out of $10(60 \%)$ patients in the L-CsA and SOC-alone groups, respectively $(\mathrm{p}=0.7)$. No adverse events had a fatal outcome.

Survival for L-CsA patients improved compared with SOC-alone (45\% (five out of 11) alive compared with $0 \%$ (none out of 10 ) alive; median 4.1 versus 2.9 years; $\mathrm{p}=0.03$ (Renyi test $\mathrm{p}=0.07$ )) (figure $5 \mathrm{a}$ ). Graft survival (death and re-transplant) was similarly improved: 4.1 years L-CsA versus 2.7 years SOC-alone; six out of 11 treatment failures, one re-transplant; 10 out of 10 treatment failures, three re-transplants $(\mathrm{p}=0.01)$ (figure $5 \mathrm{~b})$. Causes of death were all chronic allograft rejection with the exception of disseminated skin cancer (L-CsA) and renal failure (SOC-alone).

\section{Discussion}

Lung transplant survival is limited and has failed to improve substantially during the past two decades. Bronchiolitis obliterans is a leading cause of death [3]. Inhalation of cyclosporine provides high bronchiolar concentrations and may arrest BOS progression [21]. This initial exploratory randomised controlled open-label trial of L-CsA provides evidence for improvement of BOS defined by the composite end-point, i.e. BOS progression-free survival, with a clinically meaningful improvement at 48 weeks $(82 \%$ L-CsA versus 50\% SOC-alone; $\mathrm{p}=0.1)$ and a three-fold arrest of BOS grade progression $(\mathrm{p}=0.05)$. Although the difference in BOS progression-free survival was not significant statistically in 21 cases, the clinical magnitude of the benefit, i.e. an absolute difference of $32 \%$, was large. Moreover, comparison of change in BOS grade from randomisation was also impressive, with a two-thirds reduction in L-CsA patients.

L-CsA significantly stabilised $\mathrm{FEV}_{1}$ and FVC compared with SOC-alone. In addition to the intergroup differences in $\mathrm{FEV}_{1}$ decline, the intragroup change in $\mathrm{FEV}_{1}$ slopes differed before and after randomisation in L-CsA, converting from a negative to positive slope; in contrast, SOC-alone controls declined functionally post-randomisation at rates similar to pre-randomisation, demonstrating the characteristic inexorable decline of $\mathrm{FEV}_{1}$ from BOS despite current SOC management without L-CsA [32, 33]. Crossover patients who were off L-CsA but started L-CsA because of ongoing deterioration showed similar $\mathrm{FEV}_{1}$ improvements. Prior investigations of bronchiolitis obliterans using aerosol cyclosporine in propylene glycol, as well as a recent study using inhaled cyclosporine for BOS following haematopoietic stem cell transplantation, have shown similar pulmonary function benefits $[20,26,34]$, as have other nonrandomised studies using immunosuppressive therapies for bronchiolitis obliterans [35].

L-CsA resulted in the improvement of long-term survival and graft survival (4.1 versus 2.9 years with SOC-alone), a finding nearly matching an observational cohort study performed at the University of Pittsburgh in the USA in 2005 comparing histological bronchiolitis obliterans patients treated with inhaled cyclosporine to SOC-alone controls (median survival 4.5 versus 2.4 years) [18]. An L-CsA survival benefit was also noted in a randomised double-blind placebo-controlled trial showing bronchiolitis obliterans could be prevented by the addition of aerosolised cyclosporine-propylene glycol [25].

Allograft histology demonstrated reduced severity and frequency of bronchiolar inflammation after L-CsA randomisation but not before randomisation and synchronous levels of IL-2 in BAL were lower in L-CsA cases after but not prior to randomisation [36]. Elevated cyclosporine concentrations in the rejecting lung 
would explain these findings $[21,28]$. Increases in BAL cytokines IFN- $\gamma$ and IL-10 were also observed in L-CsA patients; IFN- $\gamma$ regulates cellular proliferation and collagen synthesis, while IL-10 can induce immune tolerance $[37,38]$.

Although the L-CsA and SOC-alone groups were similar with reference to baseline and subsequent BOS treatments, including tacrolimus exposure, immunosuppressive augmentation cycles and azithromycin use [39], the SOC-alone cohort did have significantly higher sirolimus blood levels consistent with physician-directed attempts to control progressing BOS and lung failure. The drug dose of L-CsA was given twice a day to ensure that the beneficial dose of $5 \mathrm{mg}$ would be deposited in the lung allograft. Pharmacokinetics studies demonstrated a low vascular concentration of cyclosporine. Infections and respiratory infections were similar between groups, and L-CsA offered greatly improved tolerability and reduced treatment time with the eFlow nebuliser (10-15 min) compared with cyclosporine-propylene glycol formulations [25]. With increased experience using L-CsA in larger scale trials, systemic immunosuppressive requirements could lessen, as witnessed by reduced sirolimus exposure in L-CsA patients.

In this small, single-centre trial, the addition of inhaled L-CsA offered a substantial functional benefit without additional toxicity. Due to the exploratory nature of this study, further experience is needed to confirm the magnitude and duration of the observed effects. Patient enrolment for a phase III international multicentre trial using L-CsA for BOS has begun (CliniclaTrials.gov identifiers NCT03657342 and NCT03656926).

Acknowledgements: Jennifer McGrain and Joseph Rinaldi Jr (Dept of Medicine, University of Maryland, Baltimore, MD, USA) provided excellent research coordination and data management support, respectively. The comments of Anthony F. Suffredini (NIH Clinical Center, National Institutes of Health, Bethesda, MD, USA) are gratefully acknowledged, and we thank Si Pham (Mayo Clinic Jacksonville, Jacksonville, FL, USA) for leading the Safety and Monitoring Committee (together with Keshava Rajagopal), and Michelle Ruff (Dept of Medicine, University of Maryland) for excellent administrative assistance.

Author contributions: A. Iacono, B Griffith and M. Terrin contributed to the conception and design of this study, interpreted results, and performed or assisted with the writing and the final proofing of the article to completion. I. Timofte, K. Rajagopal, M. Wijesinha and N. Murdock formulated specific databases for data interpretation, performed the final statistical analyses and commented on all study results formally, and also revised the manuscript critically for essential intellectual content. All authors gave final approval of the manuscript to be published, and agree to be accountable for data integrity and all other essential aspects.

Support statement: We are grateful to PARI Pharma GmbH for drug and device supply for this investigation, and a research grant to the University of Maryland School of Medicine; the IPF Foundation for nursing support; and the Plylar and Riehl Foundations for generously supporting the Lung Healing Center for overall study support. Funding information for this article has been deposited with the Crossref Funder Registry.

Conflict of interest: A. Iacono reports grants from PARI Pharmaceutical outside the submitted work. In addition, he has a patent for the "Use of Aerosolized Cyclosporine for Prevention and Treatment of Pulmonary Disease" issued and is Chairman for an upcoming phase III trial "Inhaled Liposomal Cyclosporine A (L-CsA) for the treatment of Bronchiolitis Obliterans (BO)". M. Wijesinha has nothing to disclose. K. Rajagopal has nothing to disclose. N. Murdock has nothing to disclose. I. Timofte has nothing to disclose. B. Griffith has nothing to disclose. M. Terrin has nothing to disclose.

\section{References}

1 Woodrow JP, Shlobin OA, Barnett SD, et al. Comparison of bronchiolitis obliterans syndrome to other forms of chronic lung allograft dysfunction after lung transplantation. J Heart Lung Transplant 2010; 29: 1159-1164.

2 Estenne M, Maurer JR, Boehler A, et al. Bronchiolitis obliterans syndrome 2001: an update of the diagnostic criteria. J Heart Lung Transplant 2002; 21: 297-310.

3 Yusen RD, Edwards LB, Dipchand AI, et al. The Registry of the International Society for Heart and Lung Transplantation: thirty-third adult lung and heart-lung transplant report - 2016; focus theme: primary diagnostic indications for transplant. J Heart Lung Transplant 2016; 35: 1170-1184.

4 Hachem RR, Trulock EP. Bronchiolitis obliterans syndrome: pathogenesis and management. Semin Thorac Cardiovasc Surg 2004; 16: 350-355.

5 Knoop C, Haverich A, Fischer S. Immunosuppressive therapy after human lung transplantation. Eur Respir J 2004; 23: $159-171$.

6 Snyder LD, Hartwig MG, Ganous T, et al. Cytokine gene polymorphisms are not associated with bronchiolitis obliterans syndrome or survival after lung transplant. J Heart Lung Transplant 2006; 25: 1330-1335.

$7 \quad$ Kahan BD. Cyclosporine. N Engl J Med 1989; 321: 1725-1738.

8 Belperio JA, Weigt SS, Fishbein MC, et al. Chronic lung allograft rejection: mechanisms and therapy. Proc Am Thorac Soc 2009; 6: 108-121.

9 Duncan SR, Leonard C, Theodore J, et al. Oligoclonal $\mathrm{CD}^{+} \mathrm{T}$ cell expansions in lung transplant recipients with obliterative bronchiolitis. Am J Respir Crit Care Med 2002; 165: 1439-1444.

10 Duncan SR, Valentine V, Roglic M, et al. T cell receptor biases and clonal proliferations among lung transplant recipients with obliterative bronchiolitis. J Clin Invest 1996; 97: 2642-2650.

11 O'Riordan TG, Duncan SR, Burckart GJ, et al. Production of an aerosol of cyclosporine as a prelude to clinical studies. J Aerosol Med 1992; 5: 171-177. 
12 O'Riordan TG, Iacono A, Keenan RJ, et al. Delivery and distribution of aerosolized cyclosporine in lung allograft recipients. Am J Respir Crit Care Med 1995; 151: 516-521.

13 Behr J, Zimmermann G, Baumgartner R, et al. Lung deposition of a liposomal cyclosporine A inhalation solution in patients after lung transplantation. J Aerosol Med Pulm Drug Deliv 2009; 22: 121-130.

14 Muggenburg BA, Hoover MD, Griffith BP, et al. Administration of cyclosporine by inhalation: a feasibility study in beagle dogs. J Aerosol Med 1990; 3: 1-13.

15 Mitruka SN, Won A, McCurry KR, et al. In the lung aerosol cyclosporine provides a regional concentration advantage over intramuscular cyclosporine. J Heart Lung Transplant 2000; 19: 969-975.

16 Dowling RD, Zenati M, Burckart GJ, et al. Aerosolized cyclosporine as single-agent immunotherapy in canine lung allografts. Surgery 1990; 108: 198-204.

17 Keenan RJ, Duncan AJ, Yousem SA, et al. Improved immunosuppression with aerosolized cyclosporine in experimental pulmonary transplantation. Transplantation 1992; 53: 20-25.

18 Iacono AT, Corcoran TE, Griffith BP, et al. Aerosol cyclosporin therapy in lung transplant recipients with bronchiolitis obliterans. Eur Respir J 2004; 23: 384-390.

19 Iacono AT, McCurry KR, Corcoran TE. Inhalation cyclosporine: a new use in lung transplantation? Curr Opin Organ Transplant 2003; 8: 327-333.

20 Iacono AT, Keenan RJ, Duncan SR, et al. Aerosolized cyclosporine in lung recipients with refractory chronic rejection. Am J Respir Crit Care Med 1996; 153: 1451-1455.

21 Corcoran TE, Smaldone GC, Dauber JH, et al. Preservation of post-transplant lung function with aerosol cyclosporin. Eur Respir J 2004; 23: 378-383.

22 Keenan RJ, Zeevi A, Iacono AT, et al. Efficacy of inhaled cyclosporine in lung transplant recipients with refractory rejection: correlation of intragraft cytokine gene expression with pulmonary function and histologic characteristics. Surgery 1995; 118: 385-391.

23 Keenan RJ, Iacono A, Dauber $\mathrm{JH}$, et al. Treatment of refractory acute allograft rejection with aerosolized cyclosporine in lung transplant recipients. J Thorac Cardiovasc Surg 1997; 113: 335-340.

24 Iacono A, Dauber J, Keenan R, et al. Interleukin 6 and interferon-gamma gene expression in lung transplant recipients with refractory acute cellular rejection: implications for monitoring and inhibition by treatment with aerosolized cyclosporine. Transplantation 1997; 64: 263-269.

25 Iacono AT, Johnson BA, Grgurich WF, et al. A randomized trial of inhaled cyclosporine in lung-transplant recipients. N Engl J Med 2006; 354: 141-150.

26 Groves S, Galazka M, Johnson B, et al. Inhaled cyclosporine and pulmonary function in lung transplant recipients. J Aerosol Med Pulm Drug Deliv 2010; 23: 31-39.

27 Iacono AT, Smaldone GC, Keenan RJ, et al. Dose-related reversal of acute lung rejection by aerosolized cyclosporine. Am J Respir Crit Care Med 1997; 155: 1690-1698.

28 Corcoran TE, Niven R, Verret W, et al. Lung deposition and pharmacokinetics of nebulized cyclosporine in lung transplant patients. J Aerosol Med Pulm Drug Deliv 2014; 27: 178-184.

29 Verleden GM, Raghu G, Meyer K, et al. A new classification system for chronic lung allograft dysfunction. J Heart Lung Transplant 2014; 33: 127-133.

30 Glanville A, Verleden GM, Todd J, et al. Chronic lung allograft dysfunction: definition and update of restrictive allograft syndrome - a consensus report from the Pulmonary Council of the ISHLT. J Heart Lung Transplant 2019; 38: 483-492.

31 Laird NM, Ware JH. Random-effects models for longitudinal data. Biometrics 1982; 38: 963-974.

32 Song MK, De Vito Dabbs A, Studer SM, et al. Course of illness after the onset of chronic rejection in lung transplant recipients. Am J Crit Care 2008; 17: 246-253.

33 Lama VN, Murray S, Lonigro RJ, et al. Course of $\mathrm{FEV}_{1}$ after onset of bronchiolitis obliterans syndrome in lung transplant recipients. Am J Respir Crit Care Med 2007; 175: 1192-1198.

34 Gormley N, Ramos C, Reger R, et al. Inhaled cyclosporine for the treatment of bronchiolitis obliterans following hematopoietic stem cell transplantation (HSCT) or lung transplantation. Blood 2013; 122: 2057.

35 Moniodis A, Townsend K, Rabin A, et al. Comparison of extracorporeal photopheresis and alemtuzumab for the treatment of chronic lung allograft dysfunction. J Heart Lung Transplant 2018; 37: 340-348

36 Albring A, Wendt L, Harz N, et al. Relationship between pharmacokinetics and pharmacodynamics of calcineurin inhibitors in renal transplant patients. Clin Transplant 2015; 29: 294-300.

37 Antoniou KM, Nicholson AG, Dimadi M, et al. Long-term clinical effects of interferon gamma-1b and colchicine in idiopathic pulmonary fibrosis. Eur Respir J 2006; 28: 496-504.

38 Moore KW, de Waal Malefyt R, Coffman RL, et al. Interleukin-10 and the interleukin-10 receptor. Annu Rev Immunol 2001; 19: 683-765.

39 Brenden C, Haughton M, Leonard S, et al. Therapy options for chronic lung allograft dysfunction-bronchiolitis obliterans syndrome following first-line immunosuppressive strategies: a systematic review. J Heart Lung Transplant 2017; 36: 921-933. 